ARTIGOS

\section{RECLAMAÇÕES E CONHECIMENTO DO CONSUMIDOR VIRTUAL À LUZ DO CÓDIGO DE DEFESA DO CONSUMIDOR: UM ESTUDO EXPLORATÓRIO}

\section{RESUMO}

Em face dos avanços tecnológicos que propiciaram o surgimento de um consumidor mais crítico e menos passivo na relação de consumo, esta pesquisa tem como objetivo analisar reclamações de consumidores virtuais, que têm como base o Código de Defesa do Consumidor (CDC), publicadas por meio do website Reclame Aqui. Para tanto, realizou-se uma pesquisa de natureza qualitativa, por meio da técnica de análise de conteúdo com o auxílio do software Atlas Ti versão 7.2. Após analisadas 233 reclamações, os resultados indicaram que a maior parte das ocorrências de reclames diz respeito ao Direito de Arrependimento. Entretanto, constatou-se que os consumidores que mais dão continuidade ao processo de reações à insatisfação são os que enfrentam predominantemente problemas de entrega ou de defeito do produto, bem como de qualidade do serviço prestado.

Palavras-chave: Reclamações. Conhecimento do Consumidor. Código de Defesa do Consumidor (CDC).

\section{INTRODUÇÃO}

$\mathrm{O}$ e-commerce revolucionou as relações de consumo, intensificando o nível de competitividade de mercado, uma vez que empresas deixaram de competir localmente para competir globalmente, possibilitando aos varejistas novos modelos de negócios e aos consumidores conveniência, praticidade e mais flexibilidade para compras a distância e baixos custos de procura (ANDERSON, 2006; JATO et al., 2008). Esses avanços tecnológicos propiciaram o surgimento de um consumidor mais crítico e menos passivo na relação de consumo (VELLOSO; YANAZE, 2014).

Em países ocidentais como o Brasil, as empresas, hoje, relacionam-se com consumidores mais informados, mais exigentes e que reclamam mais, fato que gerou um aumento na preocupação dos empresários em ouvir essas reclamações e exigências de seus clientes (SIQUEIRA, 1995). Há mais de duas décadas, pesquisas já indicavam que os órgãos de proteção e defesa ao consumidor 
recebiam, ano após ano, um crescente número de reclamações de consumidores insatisfeitos com os mais diversos problemas de consumo. As reclamações fundamentadas, resolvidas ou não, fazem parte do Cadastro de Fornecedores Reclamados, lista publicada anualmente pelo PROCON-SP (TAKIO, 1996). Segundo Hemais e Casotti (2014), esta estatística de reclamações nos órgãos de defesa do consumidor continua aumentando.

Sabe-se, porém, que os clientes que reclamam e têm seu problema resolvido pela empresa tendem a se tornar mais fiéis do que aqueles consumidores que nunca tiveram nenhum tipo de conflito (LOVELOCK; WIRTZ; HEMZO, 2011). Nesse sentido, empresas consideram que o conhecimento e a aplicação dos direitos do consumidor não são apenas uma obrigação legal ou social, mas uma estratégia mercadológica (PAJOLI, 1994).

O conhecimento por parte dos consumidores, de modo geral, é apontado em estudos prévios como fator determinante para a reclamação (MAT et al., 2016). Em outras palavras, quanto maior o nível de instrução do consumidor, maior a propensão de que ele venha a manifestar qualquer insatisfação de consumo por meio da reclamação. Não foram encontradas, porém, pesquisas que buscassem explorar, especificamente, o conhecimento que o consumidor tem de seus direitos em situação de insatisfação de consumo e, por conseguinte, de reclamação.

Antes da elaboração da Lei $n^{\circ}$ 8.078/90 - que dispõe sobre a proteção ao consumidor - pesquisas, debates e trabalhos científicos sobre os direitos do consumidor eram muito escassos (FCESP, 1976; COIMBRA, 1979; GUAGLIARDI; MAZZON; BAPTISTELLA FILHO, 1981). Hoje, embora esses direitos já sejam disseminados, estudar o conhecimento que o consumidor tem dessa legislação continua sendo um assunto pouco abordado no âmbito acadêmico internacional e, sobretudo, no contexto nacional (SILVA; URDAN, 2008). Essa realidade vai de encontro ao fato de que o conhecimento que o consumidor tem sobre seus direitos é um dos aspectos fundamentais para que a população brasileira atinja o status de uma sociedade consumidora mais democrática e cidadã (WADA; OLIVEIRA, 2013).

É consenso na literatura jurídica, porém, que o brasileiro possui, à sua disposição, uma excelente e avançada legislação protecionista que lhe garante a defesa individual e coletiva da comunidade consumerista (MENEZES, 2003; JATO et al., 2008; BENJAMIN; MARQUES; BESSA, 2012; NUNES, 2015). No entanto, na área da Administração, pouco se sabe a respeito de como essa legislação vem sendo utilizada pelo consumidor como embasamento para avaliar o processo de consumo e, porventura, para reportar insatisfações e exigir das empresas atitudes de reparação.

Diante do exposto, o objetivo deste trabalho é analisar reclamações de consumidores virtuais que têm como base o Código de Defesa do Consumidor (CDC), publicadas por meio do website Reclame Aqui. A escolha dessa plataforma virtual justifica-se por ser, segundo Hor-Meyll et al. (2012), o principal site brasileiro dedicado a reclamações e o quarto maior em quantidade de comentários sobre experiências de compra, ficando atrás apenas de sites de relacionamentos (E-LIFE, 2008; EXAME, 2015). Ademais, optou-se por investigar as reclamações relacionadas a e-commerce devido a sua atual representatividade no cenário comercial (VELLOSO; YANAZE, 2014).

Para alcançar o objetivo proposto, foi feita uma pesquisa de natureza qualitativa, por meio da técnica de análise de conteúdo, das reclamações divulgadas no Reclame Aqui. As categorias teóricas utilizadas como guias para a análise têm origem de artigos do CDC. Essas são: Arrependimento; Problemas na entrega; Defeito, vício ou qualidade; Propaganda enganosa; Cobrança indevida ou abusiva; Atendimento deficiente; Falha no pós-compra (garantia ou troca).

A relevância desta pesquisa está expressa nas contribuições encontradas para a lacuna teórica sobre o assunto, mediante a escassez de trabalhos acadêmicos realizados, tanto na- 
cional quanto internacionalmente, acerca do conhecimento que o consumidor possui sobre seus direitos (GUAGLIARDI; MAZZON; BAPTISTELLA FILHO, 1981; WADA; OLIVEIRA, 2013; DOMMEYER; GROSS, 2003; ALI et al., 2014) . Ademais, os estudos para avaliar o conhecimento do consumidor sobre seus direitos contribuem para a compreensão das relações de comportamento do mercado local e o desenvolvimento de estratégias adequadas para a promoção e comercialização de bens e serviços (LIMA; OLIVEIRA, 2014).

Além desta introdução, este artigo é composto de mais quatro seções. A segunda seção consiste na revisão literária, a terceira aborda os aspectos metodológicos, a quarta, a análise dos resultados e, por fim, a conclusão do estudo.

\section{REFERENCIAL TEÓRICO}

Essa segunda seção do trabalho está dividida em duas partes. No primeiro subitem, é apresentado um breve histórico sobre o Código de Defesa do Consumidor e uma síntese teórica sobre o conhecimento do consumidor acerca de seus direitos. No segundo subitem, são relatados conceitos básicos sobre insatisfação e reclamação do consumidor.

\subsection{O CDC E O CONHECIMENTO DO CONSUMIDOR}

Há algumas décadas, artigos foram desenvolvidos com o objetivo de explorar o direito do consumidor e as relações de consumo (PELTZMAN, 1973; SIGELMAN; SMITH, 1980; SCHWARTZ, 1997). Ainda na atualidade, o assunto continua sendo abordado (ALI et al., 2014; SCHULTE-NÖLKE, 2015; GREENWOOD; DWYER, 2015; BANGA; KUMAR; WADHWA, 2016).

No Brasil, o início da preocupação com as relações de consumo deu-se a partir da década de 1950, quando foram sancionadas algumas leis sobre o assunto, entre as quais destaca-se a Lei de Economia Popular (Lei 1.221/51), a
Lei Delegada n. ${ }^{\circ}$ 4/62 e a Constituição Federal de 1967 , com a emenda n. ${ }^{\circ} 1$ de 1969 , que cita a defesa do consumidor (TEFFÉ, 2013). Para Benjamin, Marques e Bessa (2012), este aumento da preocupação com a proteção jurídica do consumidor repercutiu diretamente na Constituição Federal de 1988, início da codificação tutelar dos consumidores no Brasil, sendo a proteção ao consumidor classificada como um Direito Fundamental (art. 5, XXXII).

Até 1990, quando o CDC foi sancionado, o consumidor brasileiro era carente de um sistema de normas gerais direcionado particularmente para a regulação das relações de consumo. A tutela do consumidor nas relações de consumo era realizada, com base nas regras obsoletas do Código Civil de 1916 e do Direito Comercial (COMPARATO, 2011; NUNES, 2015).

Na década de 1980, antes mesmo da elaboração da legislação consumerista, uma das primeiras pesquisas realizadas no Brasil, por Guagliardi, Mazzon e Baptistella Filho (1981), destacou índices de conhecimento que os consumidores possuíam sobre os órgãos oficiais de fiscalização e de defesa do consumidor: $65 \%$ declararam conhecer a Superintendência Nacional do Abastecimento (SUNAB); 24\% declararam conhecer o Programa de Proteção e Defesa do Consumidor (PROCON) e 19\% declararam conhecer o Conselho de Defesa do Consumidor (CONDECON).

Outra pesquisa, realizada em 2013, revelou que o brasileiro conhece mais os seus direitos como consumidor, porém, de fato, pouco os reclama. Os resultados da pesquisa apontaram que $72 \%$ conhecem, ou já ouviram falar do $\mathrm{CDC}$, e $82 \%$ dos brasileiros afirmam que conhecem ou têm certo grau de familiaridade com os direitos do consumidor. Apesar disso, apenas $11 \%$ dos consumidores já consultaram o Código (WADA; OLIVEIRA, 2013).

Segundo Wada e Oliveira (2013), as pessoas que mais conhecem e reclamam o conteúdo do CDC são os pertencentes às classes sociais mais elevadas. Heung e Lam (2003) concordam, defendendo que a propensão de o consumidor reclamar é menor, na medida em 
que seus níveis de renda e educação também forem baixos.

Um estudo com consumidores de baixa renda revelou que, antes de buscarem seus direitos legais para enfrentar as empresas, os consumidores buscam a informalidade, pois acreditam ser a maneira mais fácil ou rápida para resolver problemas. Este aspecto sugere a insuficiência de conhecimento do consumidor em relação a seus direitos (HEMAIS; CASOTTI, 2014). Nesse sentido, para Pajoli (1994), a questão da educação é ponto fundamental para tornar o consumidor mais crítico e preparado para exercer hábitos de consumo de padrões mais elevados, e a escolaridade é um fator determinante para o conhecimento do Código (WADA; OLIVEIRA, 2013).

A constante exposição a informações possibilita o consumidor a criar uma base de conhecimento mais consistente (NAGLE; HOLDEN, 2002). À medida que o consumidor possui mais conhecimento sobre o mercado de consumo, ele pode pensar considerando um maior número de variantes e tomar decisões mais precisas e coerentes dando-lhe maior benefício na relação de consumo (SILVA; URDAN, 2008).

Atualmente, o consumidor é intensamente solicitado a tomar decisões de compra de diversos produtos e serviços sem ter o conhecimento prévio suficiente para fazê-lo, ao mesmo tempo em que a publicidade intensa traz imagens exageradas ou, até mesmo, enganosas sobre tais produtos (LIMA; OLIVEIRA, 2014).

A Australian Securities and Investments Commission (ASIC) identificou uma série de benefícios associados com o aumento da consciência dos direitos dos consumidores. Independentemente da renda, idade ou do sexo, um nível mais elevado da consciência que os consumidores possuem sobre os seus direitos cria maiores perspectivas de oportunidades econômicas, bem-estar e segurança financeira em longo prazo, os quais contribuem para o geral bem-estar emocional e físico para indivíduos e famílias (ALI et al., 2014).

\subsection{INSATISFAÇÃO E RECLAMAÇÕES}

Inicialmente, o conceito de satisfação foi tratado exclusivamente como um tipo de atitude (DAY, 1984). Depois, passou a ser reconhecida pela comparação entre o nível de desempenho percebido pelo consumidor e a qualidade ou outros efeitos utilizados como parâmetros (OLIVER; WESTBROOK, 1991). Engel, Blackwell e Miniard (1993) corroboraram afirmando que a satisfação é uma avaliação feita após o consumo de um produto ou serviço, que supera ou, pelo menos, alcança as expectativas do consumidor. Para Smith e Bolton (2002), esta avaliação é cognitiva, porém detém traços afetivos e emocionais. Hor-Meyll et al. (2012) conclui dizendo que as expectativas do consumidor sobre o desempenho do produto ou serviço antes de sua aquisição são um dos elementos essenciais para o julgamento da satisfação.

Por outro lado, a insatisfação era considerada como uma experiência individual, porém há evidências de que, quando consumidores insatisfeitos se encontram, a interação reforça a antipatia pela empresa que causou a insatisfação, motivando-os mutuamente a reclamarem seus direitos (WARD; OSTROM, 2006). Oliver (1997) explicou insatisfação como um julgamento de um produto ou serviço, ou alguma de suas peculiaridades, que gera um nível de desconforto na percepção de valor esperado.

Existem três possíveis ações que o consumidor insatisfeito pode tomar:

a) ações "públicas" (queixa à empresa, aos órgãos fiscalizadores públicos ou privados e ações legais para obter ressarcimento);

b) ações "privadas" (boicote ou abandono ao fabricante ou revendedor e divulgação boca a boca da experiência negativa) e;

c) não tomar nenhuma ação (LOVELOCK; WIRTZ; HEMZO, 2011).

Possível ação posterior à insatisfação, Claro, Souza e Mena (2013) resumiram o conceito de reclamação como a consequência de 
um ato de consumo, na qual o consumidor vivencia uma insatisfação, e perante isso, precisa de uma compensação.

O processo de reclamação consiste basicamente em quatro estágios:

a) o consumidor confirma sua decisão;

b) avalia sua experiência;

c) conclui sua satisfação ou insatisfação; e, finalmente;

d) formula sua resposta futura, que pode estar direcionada ao abandono, à reclamação ou à lealdade ao produto, serviço ou fornecedor (SHETH; MITTAL; NEWMAN, 2001).

Jato et al. (2008), em sua perspectiva, identificaram, no processo pós-compra, cinco ações comportamentais de consumidores insatisfeitos:

a) reclamar com a loja ou o fabricante;

b) parar de comprar a marca ou na loja;

c) promover comunicação boca a boca negativa;

d) reclamar com órgãos privativos ou governamentais e;

e) iniciar processo jurídico.

Segundo Beber e Rossi (2006) e Massad, Heckman e Crowston (2006), as experiências negativas são sempre mais disseminadas do que as positivas. Este contexto gerou o conceito de marketing defensivo, cujo objetivo é diminuir a troca de fornecedores e a rotatividade de clientes (FORNELL; WERNERFELT, 1987). A explicação é bastante simples: é mais barato manter um cliente que a empresa já possui que obter um novo cliente, e o instrumento essencial para a retenção do consumidor é a satisfação (KOTLER; KEVIN, 2012), pois o momento mais propício para o cliente trocar de marca é quando está insatisfeito (BEBER; ROSSI, 2006).

Nesse sentido, de acordo com os resultados de pesquisa prévia, quanto maior for a renda familiar, o grau de instrução e a idade do consumidor, maior será a sua propensão à insatisfação (BEBER; ROSSI, 2006). Na pesquisa feita por Guagliardi, Mazzon e Baptistella Filho (1981), afirma-se que $29 \%$ dos consumidores insatisfeitos reclamam no local de com- pra, enquanto $25 \%$ respondem que não tomam nenhuma atitude, fato que evidencia a posição passiva do consumidor brasileiro e a falta de hábito de se dirigir a órgãos competentes, talvez por descrença ou desconhecimento. Outro dado relevante é a descrença dos entrevistados, em que $20 \%$ dos respondentes declararam que não há possibilidade de solução quanto aos problemas de consumo (GUAGLIARDI; MAZZON; BAPTISTELLA FILHO, 1981).

Por outro lado, os comentários on-line são uma forma de informação do consumidor que vem ganhando cada vez mais valor comercial e influência dos consumidores (HUNT, 2015). O consumidor que teve suas expectativas frustradas, muitas vezes, utiliza apenas as redes sociais para externar a insatisfação por meio de reclamações, deixando de procurar os órgãos oficiais de defesa dos consumidores (OLIVEIRA; HENRIQUES; PAULA, 2012).

Segundo Velloso e Yanaze (2014), a tendência do consumidor de utilizar as Redes Sociais para compartilhar suas insatisfações tende a se ampliar. Os consumidores podem-se juntar para trocar comentários negativos pela internet, que é um poderoso veículo para expressar a insatisfação (WARD; OSTROM, 2006; GRÉGOIRE; TRIPP; LEGOUX, 2009), a ponto das reclamações on-line serem consideradas uma ameaça para as empresas (ARIELY, 2007; MCGREGOR, 2008). Sobretudo, investigar sites e comunidades virtuais por meio de observação não intrusiva permite que empresas conheçam necessidades de seu público, extraindo sugestões para a definição de estratégias e para o desenvolvimento ou a modificação de produtos e serviços (SCHIFFMAN; SHERMAN; COHN, 2008).

\section{PROCEDIMENTOS METODOLÓGICOS}

Considerando o objetivo geral deste trabalho, de analisar reclamações de consumidores virtuais que têm como base o Código de Defesa do Consumidor (CDC), publicadas por meio do website Reclame Aqui, percebe-se que ele corrobora com o objetivo da pesquisa exploratória, que consiste em "buscar entender as 
razões e motivações subentendidas para determinadas atitudes e comportamentos das pessoas" (RÉVILLION, 2003, p. 3).

Neste intento, a presente pesquisa foi desenvolvida em caráter qualitativo. De acordo com Pinheiro et al. (2004), no estudo qualitativo, dados não mensuráveis são sondados, como: sentimentos, impressões, percepções e intenções. Segundo Bauer e Gaskell (2002), a pesquisa qualitativa não envolve números e trabalha com análises das realidades sociais, tendo, como fundamento, o método descritivo e interpretativo para a obtenção de conteúdo mais preciso.

Assim, entre os métodos qualitativos, elegeu-se a pesquisa documental, sob a orientação de Godoy (1995), a qual pode revestir-se de caráter inovador e possibilitar contribuições importantes no estudo de alguns temas. Os documentos, em geral, são objetos que possuem uma existência semipermanente e concreta, a qual revela indiretamente o meio social e as pessoas que os criaram (PAYNE, G.; PAYNE, J., 2004). Os documentos estão normalmente disponíveis em texto (impresso) e também podem ser disponibilizados em formato eletrônico (FLICK, 2009).

Em um segundo momento, foi realizada uma análise de conteúdo. Esse tipo de análise, conforme explica Bardin (2011), considera a palavra em seu conteúdo manifesto, possibilitando a inferência sobre seu conteúdo de acordo com um contexto social específico.

Partindo dessas definições, consideraram-se as reclamações postadas por consumidores de várias partes do País, na plataforma virtual $<$ www.reclameaqui.com.br $>$. As reclamações analisadas foram consideradas como documentos pessoais de natureza pública. Complementa-se que, de acordo com que os documentos analisados, eles podem ser considerados primários, pois foram produzidos pelos próprios usuários do portal virtual (LAKATOS; MARCONI, 2003).

O website "Reclame Aqui" foi escolhido como canal de coleta dos dados por ser o quarto maior site em quantidade de comentários sobre experiências de compra, ficando atrás apenas de sites de relacionamentos (EXAME, 2015; E-LIFE, 2008) e pela expressiva quantidade de acessos (2.5 milhões de visitas mensais e 4.000 novas reclamações diárias). Além disso, é utilizado exclusivamente como canal para expressar insatisfação com compras, enquanto os demais são redes sociais utilizadas com inúmeros intuitos, o que poderia ser problemático para a coleta e análise dos dados. O período da pesquisa compreende os dias entre $1^{\circ}$ de setembro de 2015 a 31 de maio de 2016.

Em função da grande quantidade de comentários que são postadas diariamente na plataforma e para selecionar apenas comentários relacionados ao assunto pesquisado, na coleta, foram elencadas sete palavras-chave para filtrar a busca ("direito do consumidor"; "direitos do consumidor", "código de defesa do consumidor", "CDC", "ação judicial", "meus direitos", "processar"). É importante ressaltar que, mesmo utilizando essas palavras-chave, os resultados da busca ainda eram muito expressivos.

Foram selecionadas 233 reclamações publicadas nesse período. Seguindo orientações de Teixeira (2003), a finalização desse processo ocorreu por saturação de dados, ou seja, quando as informações começaram a se repetir, não fornecendo novos materiais para enriquecer o estudo.

As reclamações foram copiadas na íntegra e tratadas por análise de conteúdo, utilizando o software Atlas Ti versão 7.2. Para a análise deste trabalho, os sujeitos são identificados pelo nome Reclamante, seguido pela ordem cronológica e reclamação e ainda, pela categoria da reclamação, como no seguinte exemplo: (Reclamante 1, Arrependimento).

As categorias teóricas utilizadas para a análise das reclamações resumem os artigos do CDC que foram referenciados. Essas são: Arrependimento; Problemas na entrega; Defeito, vício ou qualidade; Propaganda enganosa; Cobrança indevida ou abusiva; Atendimento deficiente; Falha no pós-compra (garantia ou troca). 


\section{ANÁLISE DOS DADOS}

Em etapa prévia à triagem dos dados a ser analisados, para obter uma visão de um patamar global, foram consideradas todas as reclamações publicadas no site Reclame Aqui entre os dias 2 de janeiro e 31 de março (início do ano corrente até o ponto de saturação das informações) sem qualquer filtro de seleção. Observou-se que, das reclamações divulgadas no site, 233 mencionavam o CDC, de forma geral ou referenciando diretamente artigos específicos do código.

Adiante, com o intuito de analisar as reclamações dos consumidores embasadas no CDC, verificou-se o teor das reclamações que faziam menção ao código e quais artigos eram citados com maior frequência. É importante ressaltar que, entre as reclamações que faziam alusão ao $\mathrm{CDC}$, apenas foram selecionadas aquelas que apresentavam coerência entre o problema ocorrido, que gerou a reclamação, e o que a legislação dá suporte.
Por fim, com base no que aponta Velloso e Yanaze (2014) sobre as peculiaridades da compra on-line, optou-se por dividir as categorias de reclamações em dois grupos: aquelas oriundas de problemas com o produto e as que têm origem em problemas de serviço. Em resultado, apenas a categoria Defeito, Vício ou Qualidade tem relação, unicamente, com o produto. Cobrança indevida ou abusiva, Atendimento deficiente e Problemas na Entrega são categorias de reclamações que advêm de problemas de serviço. Por sua vez, as categorias Arrependimento, Propaganda Enganosa e Falha no Pós-Compra foram identificadas como pertencentes a ambos os grupos, uma vez que o conteúdo das reclamações centradas nesses problemas apontam irregularidades em ambos, produto e serviço agregado. Essas relações estão mapeadas na Figura 1.

\begin{tabular}{|c|c|c|c|}
\hline Categorias de Análise do Estudo & Artigo CDC & $\begin{array}{l}\text { Incidência de } \\
\text { reclamações / } \\
\text { conhecimento }\end{array}$ & Percentual \\
\hline Arrependimento & 49 & 90 & $38,6 \%$ \\
\hline
\end{tabular}

\begin{tabular}{|c|c|c|c|}
\hline Problemas na entrega & $26,39,40$ & 56 & $24 \%$ \\
\hline Defeito, vício ou qualidade & $4,12,14,18,19,20$ e 26 & 41 & $17,7 \%$ \\
\hline Propaganda enganosa & 6 e 37 & 15 & $6,4 \%$ \\
\hline Cobrança indevida ou abusiva & 42 & 11 & $4,7 \%$ \\
\hline Atendimento deficiente & $4,12,39$ & 10 & $4,3 \%$ \\
\hline $\begin{array}{c}\text { Falha no pós-compra } \\
\text { (garantia ou troca) }\end{array}$ & $13,22,24,31$ e 50 & 233 & $4,3 \%$ \\
\hline TOTAL & & & $100 \%$ \\
\hline
\end{tabular}

Quadro 1 - Resultados da pesquisa

Fonte: elaborado pelos autores (2016).

Posteriormente, a partir desse filtro, foram identificadas sete categorias de análise para presente pesquisa: Arrependimento; Problemas na entrega; Defeito, vício ou qualidade; Propaganda enganosa; Cobrança indevida ou abusiva; Atendimento deficiente; Falha no pós-compra (garantia ou troca), conforme mostra o Quadro 1. 


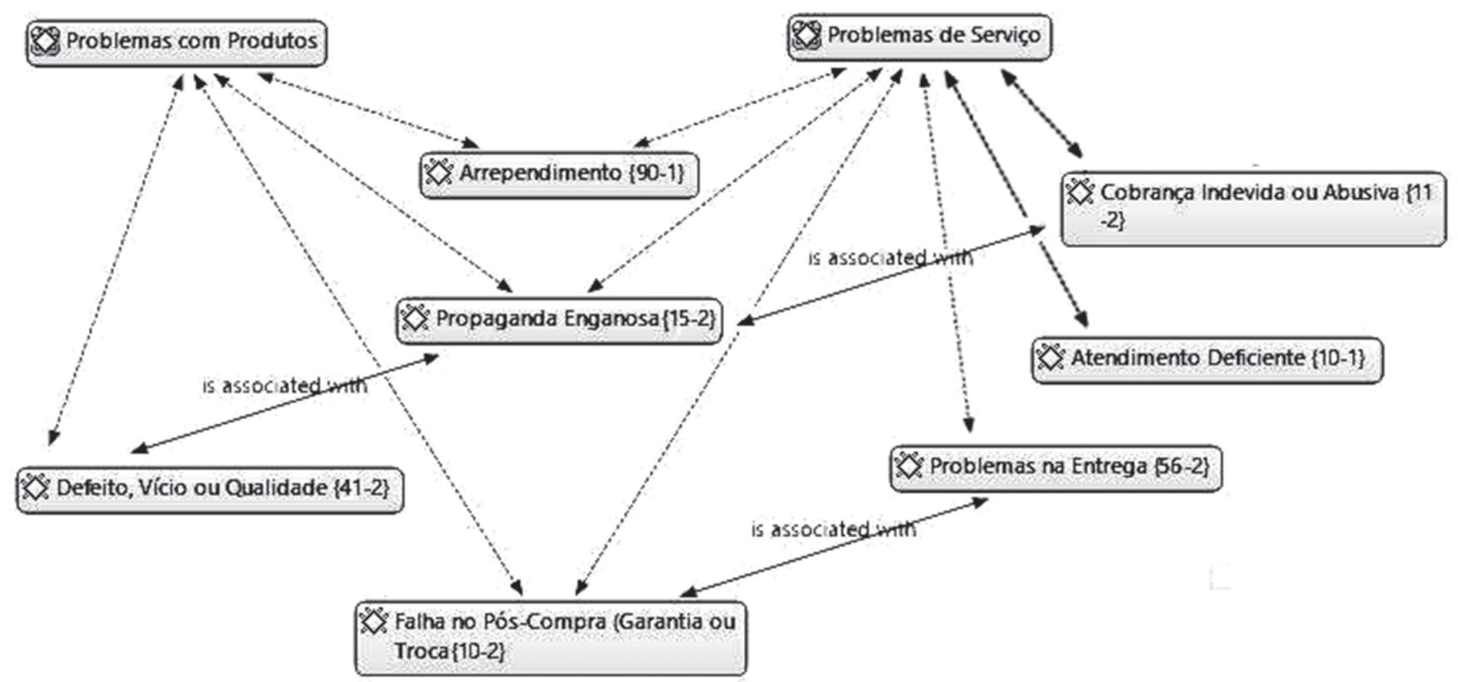

Figura 1 - Reclamações de consumidores

Fonte: dados da pesquisa por ATLAS Ti versão 7.2 (2016).

Especificamente no que diz respeito à categoria Arrependimento, esta corresponde à maior recorrência de reclamações embasadas pelo CDC, com 90 casos ou $38,6 \%$ do total analisado. Percebeu-se que os reclamantes que alegam ter tido o direito de Arrependimento ferido, comumente relatam um caso que envolve a insatisfação decorrente da aquisição de um produdo, bem como do serviço prestado quando manifestado o desejo de devolução:

Mandei [o aparelho celular] duas vezes para assistência com o mesmo problema [...] e a central de atendimento disse que só na terceira vez que podia recorrer do reembolso, isso é mentira, pois conforme o Artigo 49, eles na segunda vez tinham que ter me oferecido outro aparelho ou o reembolso, isso não ocorreu [...]. Estou muito insatisfeita com o produto e decepcionada com a empresa (RECLAMANTE 2, ARREPENDIMENTO).

Ainda sobre o Direito de Arrependimento, é válido ressaltar que é necessário que o consumidor faça uma interpretação sadia com base consistente não só no referido artigo, mas de toda legislação protecionista e cívil, para inferir com segurança se o consumidor é digno de reclamar tal direito.
Ao encontro do discurso de Massad, Heckman e Crowston (2006), que apontam falhas na entrega como antecedentes da insatisfação, a categoria Problemas na Entrega também se apresenta, neste estudo, como fator determinante na avaliação do processo de consumo:
No mês de novembro de 2015, fiz a compra de três almofadas do site Cois- as Boas para dar de presente de casa- mento à minha amiga. A entrega que deveria ter ocorrido 10 dias depois, se tornou um pesadelo. [...] Eu recebi em dezembro duas almofadas e até agora [18/02/2016] não recebi a almofada que falta. Preciso de uma resolução urgente, já paguei por estes produtos. Até hoje não pude entregar o presente à minha melhor amiga, olha que cons- trangimento que esta empresa está me causando! [...] (RECLAMANTE 14, PROBLEMAS NA ENTREGA).

Foram constatados 56 casos reclamações centradas em Problemas na entrega, que representam $24 \%$ do total selecionado. É relevante observar que essa categoria não está relacionada a problemas com o produto em si e, ainda assim, é a segunda reclamação em percentual e, 
por conseguinte, referenciada pelo consumidor como um direito assegurado pelo CDC.

No tocante a Defeito, Vício ou Qualidade, os resultados da análise detêm similaridade com os estudos de Cho et al. (2002) e de Hor-Meyll et al. (2012), sendo, nesta pesquisa, a terceira categoria em frequência de reclamações embasadas no CDC, com 41 incidências e $17,7 \%$ do total.

[Adquirido por loja online] o livro pula da página 1552 para a página 1585 , sendo que constam páginas do fim do livro e em branco neste intervalo. Entrei em contato com a Saraiva pelo chat online questionando se poderia efetuar a troca do livro na loja física, visto se tratar de um vício oculto [...]. Me informaram que o prazo para troca na loja seria de 07 dias após o recebimento. Me parece que a Saraiva não sabe a diferença entre direito de arrependimento, vício oculto e vício aparente. O Código de Defesa do Consumidor, em seu artigo 26, parágrafo $3^{\circ}$, disciplina que o prazo decadencial nos casos de vício oculto começa a fluir a partir da data do conhecimento do vício. O prazo de 07 dias se aplica quando se tratar de direito de arrependimento. Logo, como meu caso se trata de vício oculto, solicito a troca do produto em alguma das lojas físicas existentes na minha cidade com a maior brevidade possível e sem custos (RECLAMANTE 22, DEFEITO, VÍCIO OU QUALIDADE).

A fala do reclamante aponta o desconhecimento dos atendentes da empresa no que tange ao $\mathrm{CDC}$, o que vai ao encontro do que explana Wada e Oliveira (2013). Ademais, é possível presumir que categoria de Defeito, Vício ou Qualidade, ainda que relacionada apenas a problemas com produtos, tenha recebido influência de problemas de serviço devido a sua associação com Propaganda Enganosa, que está relacionada a ambos os problemas.

Em decorrência dessa mesma associação, sendo Defeito, Vício ou Qualidade relacionado diretamente a produtos, a Propaganda Enganosa poderia receber influência e constituir mais amplamente as reclamações que envolvem problemas com produtos. No entanto, foi observado nas falas da categoria Propaganda Enganosa (com 15 reclamações, $6,4 \%$ do total) que elas estão majoritariamente ligadas a preço, o que mostra ser, neste caso, a categoria de Cobrança Indevida ou Abusiva (com 11 reclamaçãoes e 4,7\% do total) mais associada, como reforçam os reclames que seguem:

O cliente é atraído para a página da oferta e lá é traído pela empresa ao ser apresentado a um preço mais caro, diferente do anunciado (RECLAMANTE 13, PROPAGANDA ENGANOSA/ COBRANÇA INDEVIDA OU ABUSIVA).

Anunciou um produto com desconto mas no ato do pagamento mudaram o desconto (RECLAMANTE 6, PROPAGANDA ENGANOSA/ COBRANÇA INDEVIDA OU ABUSIVA).

Quero o produto do valor anunciado!!! Ou o EXTRA.COM não tem credibilidade ou desconhece do código de defesa do consumidor (RECLAMANTE 7, PROPAGANDA ENGANOSA/ COBRANÇA INDEVIDA OU ABUSIVA).

Considerando a regular menção por parte dos consumidores ao contato com a empresa por meio dos chats on-line, observada no conteúdo de variadas categorias desta pesquisa, atribui-se ao atendimento um papel essencial para a satisfação do consumidor, mesmo nas compras realizadas em ambiente virtual. Os maus atendimentos ao cliente, comuns em ambiente de loja física, foram também identificados na fase de pós-compra on-line, tanto por via website quanto por telefone, mas com poucas ocorrências, 10 das 233, o que representa um percentual de $4,3 \%$.

Como pode você entrar em contacto na central onde os atendentes não tem senso e nem conhecimento do CDC? Será difícil parar de fazer o consumidor de palhaço e os atendentes atendere ra (RECLAMANTE 4, ATENDIMENTO DEFICIENTE).

Com a mesma representatividade, $4,3 \%$ ou 10 reclamações embasadas no CDC, a Falha 
no Pós-Compra (garantia ou troca) é representada pela seguinte fala:

Até o presente momento aguardo retorno do setor responsável. Enviei o telefone e o mesmo passou do prazo de 30 dias previsto no Código de Defesa do Consumidor, além dos atendentes identificarem que o smartphone também estava com problemas. Já mandei diversos recados a mais de 15 dias e não obtive resposta. Já tem quase 3 meses. Aguardo contato (RECLAMANTE 8, FALHA NO PÓS-COMPRA).

\section{1 REAÇÕES}

Além da menção ao CDC como aporte às reclamações, pôde-se perceber, nas categorias previamente elencadas, um teor de continuidade mediante a promessa de ações futuras, que vão além da exposição da insatisfação no website, como a descontinuidade da relação consumidor/ empresa, a propagação boca a boca negativa da empresa e a ameaça de acionar a empresa judicialmente, em concordância ao que explana Sheth, Mittal e Newman (2001). Na presente pesquisa, essas prováveis continuidades do estado de insatisfação foram intituladas Reações.

É relevante apontar que três das categorias trabalhadas - Defeito Vício ou Qualidade, Problemas na Entrega e Arrependimento - obtiveram destaque entre as demais pela maior frequência de reclamações com Reações, conforme pode ser observado na Figura 2.
A categoria Problemas na Entrega foi aquela percebida como tendo a maior recorrência de consumidores que demonstram, em sua fala, a intenção de agir contra a empresa em continuidade à reclamação em ambiente virtual, conforme pode ser observado na transcrição que segue:

Comprei cinco livros, 3 já foram enviados, 2 ainda estão pendentes, porém o prazo já está estourado. Conforme o Código de Defesa do Consumidor, existe quebra do contrato. Entrei em contato com vocês [empresa] na terça-feira, dia que vencia o contrato, via chat, e ficaram de me contatar dando uma posição, porém até hoje ninguém me contatou. Amanhã estarei dando queixa no Procon, por descumprimento de contrato (RECLAMANTE 11, PROBLEMAS NA ENTREGA).

É válido ressaltar a associação entre Falha no Pós-Compra e Problemas na Entrega, indicada na Figura 1, como possível potencializador da incidência de Reações advindas dessa categoria, uma vez que, quando identificados dois descumprimentos do CDC em uma única ocorrência, presume-se que o consumidor venha a se sentir mais lesado e que, portanto, deseje ir além do manifesto de sua insatisfação, acionando órgãos de defesa, como é o caso do Reclamante 11.

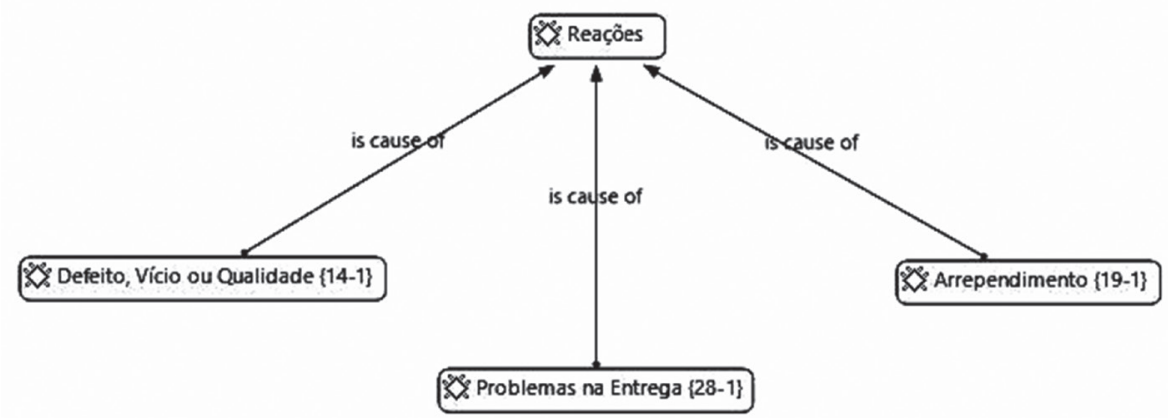

Figura 2 - Reações de consumidores

Fonte: dados da pesquisa por ATLAS Ti versão 7.2 (2016). 
Da mesma forma, o fato de a Propaganda Enganosa estar associada à categoria de Defeito, Vício ou Qualidade poderia levar o consumidor a se sentir mais injustiçado, o que, possivelmente, influenciou as Reações que foram observadas com frequência nas reclamações de Defeito, Vício ou Qualidade. O trecho a seguir mostra essa associação:

No momento da compra fui informada que compras acima de $\mathrm{R} \$ 100,00$ eu teria direito a 3 brindes, dessa forma, escolhi mais dois produtos (todos são perfumes), escolhi os três brindes, e finalizei a compra. [...] Quando minha compra chegou tentei abrir o primeiro perfume, e não abre de jeito nenhum. Procurei os brindes que havia escolhido, no entanto veio apenas 1 (DOS 3 PROMETIDOS). [...] Entrei em contato no chat, no qual a atendente negou a devolução do produto com defeito. Informou ainda que em minha compra não foi selecionado nenhum brinde. Demonstrando ainda propaganda enganosa. [...] Apelarei para os meios judiciais, afinal estão me desrespeitando como CONSUMIDORA, bem como estão desrespeitando a própria LEI. Segue abaixo, apenas para informação, o texto da lei em sua íntegra [...] (RECLAMANTE 39, DEFEITO, VÍCIO OU QUALIDADE).

A categoria de Arrependimento, a mais frequente entre as reclamações embasadas no CDC (38,6\%), também foi percebida no conteúdo das reclamações como causadora de Reações. No entanto, a intensidade da insatisfação parece ser menor, uma vez que se observaram, mais frequentemente, reações apenas de descontinuidade da relação consumidor/empresa, como a que segue:

Comprei um produto e desisti da compra nos 7 dias previstos pelo CDC, e solicitei a devolução do valor pago e para minha surpresa a loja resolveu descontar $5 \%$ do valor que paguei pelo produto antes da devolução. A loja criou um desconto para devolver o dinheiro, é um absurdo total. Total desrespeito ao consumidor! NUNCA MAIS COMPRO NADA NESTA LOJA!!!! (RECLAMANTE 35, ARREPENDIMENTO).

Alem de não estar associada a outras categorias de reclamação, o que pode ter amenizado a intensidade da insatisfação, o Arrependimento está relacionado a ambos: problemas com produtos e problemas de serviço, conforme mostra a Figura 1. É prudente supor, então, que, por essa razão, essa categoria tenha causado Reações frequentemente.

\section{CONCLUSÃO}

Neste estudo, procurou-se analisar reclamações de consumidores virtuais que têm como base o Código de Defesa do Consumidor (CDC), publicadas por meio do website Reclame Aqui. O estudo revela contribuição eminentemente teórica, em virtude da escassez de trabalhos acadêmicos produzidos sobre o conhecimento que o consumidor possui sobre seus direitos, pois o assunto continua sendo pouco abordado cientificamente, tanto no âmbito acadêmico internacional quanto, mais ainda, no contexto nacional.

Ademais, a contribuição empírica pode ser expressa no auxílio na prática da gestão, pois as empresas reclamadas talvez não tenham ainda claro conhecimento da amplitude dos problemas e de seu impacto sobre a imagem, fidelização e credibilidade da marca.

Como principais resultados, ressalta-se que a maior parte das ocorrências de reclamações analisadas diz respeito ao Direito de Arrependimento (embasado no artigo 49). Entretanto, constatou-se, também, que os consumidores que mais dão continuidade ao processo de reações à insatisfação são os que enfrentam predominantemente conflitos no atendimento pós-venda, seja por deficiência na entrega seja ainda sua não consumação. Além disso, Problemas na Entrega se apresentaram, neste estudo, 
como fator determinante na avaliação do processo decisório de consumo.

No que diz respeito aos problemas de defeito (ou vício) do produto e qualidade do serviço contratado virtualmente, eles são mais relacionados a problemas com produtos, porém receberam influência de problemas de serviço devido a sua associação com a categoria Propaganda Enganosa, a qual está relacionada a ambos os casos.

Em relação às implicações práticas desta pesquisa, é razoável mencionar, como possíveis ações do fornecedor do produto ou serviço, que é possível aproveitar as reclamações para a contribuição da gestão, corrigindo falhas (principalmente na qualidade do atendimento) apontadas por meio das reclamações e insatisfações dos reclamantes.

É importante ressaltar que este estudo examinou apenas um pequeno número de reclamações (233 no total), sendo analisadas apenas as reclamações oriundas de consumo virtual, não permitindo, assim, a generalização dos resultados obtidos. Recomenda-se, para pesquisas futuras, a análise de reclamações de lojas físicas e uma possível comparação entre a variação do nível de conhecimento do consumidor que compram on-line com o consumidor de varejo tradicional.

\section{COMPLAINTS AND KNOWLEDGE OF VIRTUAL CONSUMERS IN THE LIGHT OF THE CONSUMER PROTECTION CODE: AN EXPLORATORITY STUDY}

\section{ABSTRACT}

Technological advances have led to the emergence of more critical and less passive consumers in relation to consumption. Therefore, this research aims to analyze complaints of virtual consumers, published on the website Reclama Aqui (Complain Here), based on the Consumer Protection Code. A qualitative research was conducted, using the content analysis technique with the aid of Atlas Ti software, version
7.2. After analyzing 233 complaints, the results indicate that most of the occurrences of complaints have been related to the Right of Repentance. However, most consumers that remain dissatisfied and keep on complaining are, predominantly, those who face delivery problems, product defects and lack of quality of provided services.

Keywords: Complaints. Consumer Knowledge. Consumer Protection Code.

\section{REFERÊNCIAS}

ALI, P. et al. Consumer rights awareness of young Australians. Competition \& Consumer Law Journal, Australia, v. 22, n. 2, p. 126-150, 2014.

ANDERSON, C. A cauda longa: do mercado de massa para o mercado de nicho. Rio de Janeiro: Elsevier, 2006.

ARIELY, D. The customers' revenge: HBR case study. Harvard Business Review, United States, v. 85, p. 31-42, dez. 2007.

BANGA, G.; KUMAR, B.; WADHWA, K. Consumer awareness about their rights and Grievance Redressal Mechanism: an Empirical Study. International Journal of Research in Finance and Marketing, India, v. 6, n. 2, p. 73-82, 2016.

BARDIN, L. Análise de conteúdo. Tradução Luís Antero Reto e Augusto Pinheiro. São Paulo: Almedina Brasil, 2011.

BAUER, M. W.; GASKELL, G. Pesquisa qualitativa, com texto, imagem e som: um manual prático. 5. ed. Petrópolis: Vozes, 2002.

BEBER, S. J. N.; ROSSI, C. A. V. Estudo da Insatisfação do Consumidor nos Serviços Prestados por Assistências Técnicas Autorizadas de Automóveis. Revista de Administração Contemporânea, Rio de Janeiro, v. 10, n. 2, p. 3349, abr./jun. 2006. 
BENJAMIN, A. H.; MARQUES, C. L.; BESSA, L. R. Manual de direito do consumidor. 4. ed. São Paulo: Revista dos Tribunais, 2012.

$\mathrm{CHO}$, Y. et al. An analysis of online customer complaints: implications for web complaint management. In: ANNUAL HAWAII INTERNATIONAL CONFERENCE ON SYSTEM SCIENCES, 35., 2002, Big Island. Proceedings... Big Island, Hawaii: HICSS'02, v. 7, 2002.

CLARO, J. A. C. D. S.; SOUZA, J. R.; MENA, R. J. F. Estudo comparativo Brasil-Portugal sobre o uso de redes sociais na Internet por jovens como instrumento de reclamação junto de empresas. Revista de Administração da Unimep, São Paulo, v. 11, n. 3, p. 142-172, 2013.

COIMBRA, M. A. A política de proteção ao consumidor no Brasil: um balanço crítico. São Paulo: FUNDAP/CLACSO, 1979.

COMPARATO, F. K. A proteção do consumidor. Revista de Direito do Consumidor, São Paulo, ano 20, v. 77, p. 30-31, jan./mar. 2011.

DAY, R. L. Modeling choices among alternative responses to dissatisfaction. In: KINNEAS, T. C. Advances in Consumer Research. 11th ed. Michigan: Association of Consumer Research, 1984.

DOMMEYER, C. J.; GROSS, B. L. What consumers know and what They do: an investigation of Consumer knowledge, awareness, And use of privacy protection Strategies. Journal of Interactive Marketing, United States, v. 17, n. 2, p. 34-51, 2003. DOI: 10.1002/dir.10053.

E-LIFE. 2008. Disponível em: <http:/elife. com.br/>. Acesso em: 27 set. 2015.

ENGEL, J. F.; BLACKWELL, R. D.; MINIARD, P. W. Consumer Behavior. [S.1.]: The Dryden Press, 1993.
EXAME. Disponível em: <http://www.portalexame.com.br>. Acesso em: 27 set. 2015.

FCESP. Federação de Comércio do Estado de São Paulo. Fórum de debates: a defesa do consumidor. São Paulo: [s.n.], 1976.

FLICK, U. Uma introdução à pesquisa qualitativa. 2. ed. Porto Alegre: Bookman, 2009.

FORNELL, C.; WERNERFELT, B. Defensive marketing strategy by customer complaint management: a theoretical analysis. Journal of Marketing Research, United States, v. 24, n. 3, p. 337-346, 1987.

GODOY, A. S. A pesquisa qualitativa e sua utilização em Administração de Empresas. Revista de Administração Empresas, Rio de Janeiro, v. 35, n. 4, 1995.

GREENWOOD, V. A.; DWYER, L. Consumer protection legislation: a neglected determinant of destination competitiveness?.Journal of Hospitality and Tourism Management, Netherlands, v. 24, p. 1-8, 2015.

GRÉGOIRE, Y.; TRIPP, T.; LEGOUX, R. When customer love turns into last hate: the effects of relationship strength and time on customer revenge and avoidance. Journal of Marketing, United States, v. 73, n. 6, p. 18-32, nov. 2009.

GUAGLIARDI, J. A.; MAZZON, J. A.; BAPTISTELLA FILHO, H. Defesa do Consumidor: um estudo exploratório. Revista de Administração, São Paulo, v. 16, n. 1, p. 82-104, 1981.

HEMAIS, M. W.; CASOTTI, L. M. Insatisfações projetadas de consumidores de baixa renda. RPCA, Rio de Janeiro. v. 8, n. 4, p. 65-84, out./dez. 2014.

HEUNG, V.; LAM, T. Customer complaint behaviour towards hotel restaurant services. International Journal of Contemporary Hospitality Management, United Kingdom, v. 15, n. 5, p. 283-289, 2003. 
HOR-MEYLL, L. F. et al. Por que consumidores reclamam de compras online? BBR - Brazilian Business Review, Vitória, v. 9, n. 4, p. 133-156, out./dez. 2012.

HUNT, K. M. Gaming the System: Fake online reviews v. Consumer Law. Computer Law \& Security Review, United Kingdom, v. 31, p. 3-25, 2015.

JATO, R. et al. O comportamento do consumidor insatisfeito pós compra: um estudo confirmatório. Gestão \& Regionalidade, São Caetano do Sul, v. 24, n. 71, p. 58-67, 2008.

KOTLER, P.; KEVIN, L. Administração de Marketing. 14. ed. São Paulo: Saraiva, 2012.

LAKATOS, E. M.; MARCONI, M. A. Fundamentos de metodologia científica. 5 . ed. São Paulo: Atlas, 2003.

LIMA, A. L. B.; OLIVEIRA, A. G. R. C. Atitudes e conhecimento dos consumidores sobre os alimentos irradiados: um inquérito conduzido em Natal, Brasil. Revista Visa em Debate, Rio de Janeiro, v. 2, n. 2, p. 81-87, mar./maio 2014.

LOVELOCK, C.; WIRTZ, J.; HEMZO, M. A. Marketing de serviços: pessoas, tecnologia e estratégia. 7. ed. São Paulo: Pearson, 2011.

MASSAD, N.; HECKMAN, R.; CROWSTON, $\mathrm{K}$. Customer satisfaction with electronic service encounter. International Journal of Electronic Commerce, Unites States, v. 10, n. 4, p. 73-104, 2006.

MAT, A. et al. Determining the Educational Background Differences in Complaint Behavior Among Automobile Repairs and Service Consumers in Shah Alam, Malaysia. In: MOHD SIDEK, Noor Zahirah; ALI, Siti Meriam; ISMAIL, Mahazir. Proceedings of the ASEAN Entrepreneurship Conference 2014. [S.1.]: Springer Singapore, 2016. p. 71-79.
MCGREGOR, J. Consumer vigilantes. BusinessWeek, United States, n. 3, p. 37-58, mar. 2008.

MENEZES, J. B. A evolução dos direitos fundamentais: o direito do consumidor como um interesse difuso e a possibilidade de resgate da cooperação social. Revista Humanidades, Fortaleza, v. 18, n. 1, p. 50-67, jan./jun.2003.

NAGLE, T. T.; HOLDEN, R. K. Strategy and tactics of pricing. New Jersey: Prentice Hall, 2002.

NUNES, L. A. R. Curso de Direito do Consumidor. 10. ed. São Paulo: Saraiva, 2015.

OLIVEIRA, I. L.; HENRIQUES, M. S.; PAULA, M. A. de. A sociedade enfrenta suas organizações? interação entre organizações e sociedade nas mídias sociais articulada pelo discurso da sustentabilidade. Esferas, Brasília, v. 1, n. 1, p. 169-178, 2012.

OLIVER, R. L. Satisfaction: a behavioral perspective on the consumer. New York: McGraw-Hill, 1997.

OLIVER, R. L.; WESTBROOK, R. A. The dimensionality of consumption emotion patterns and consumer satisfaction. Journal of Consumer Research, United States, v. 18, n. 1, p. 84-91, jun. 1991.

PAJOLI, A. C. L. G. Aspectos do comportamento dos consumidores relacionados à proteção e defesa de seus direitos. Caderno de Pesquisas em Administração, São Paulo, v. 10, n. 2, $2^{\circ}$ sem. 1994.

PAYNE, G.; PAYNE, J. Key Concepts in Social Research. London: Sage Publications, 2004.

PELTZMAN, S. An evaluation of consumer protection legislation: the 1962 drug amendments. The Journal of Political and Economy, Chicago, v. 81, n. 5, p. 1049-1091, 1973. 
PINHEIRO, R. M. et al. Pesquisa qualitativa. In: PINHEIRO, R. M. et al. Comportamento do consumidor e pesquisa de mercado. Rio de Janeiro: Editora FGV, 2004. p. 125-141.

RÉVILLION, A. S. P. A utilização de pesquisas exploratórias na área de marketing. Revista Interdisciplinar de Marketing, Maringá, v. 2, n. 2, p. 21-37, jul./dez. 2003.

SCHIFFMAN, L.; SHERMAN, E.; COHN, D. "Looking-In" on global consumer-users: to develop better product feature sets. In: EVOLUTION AND REVOLUTION IN THE GLOBAL KNOWLEDGE ECONOMY: ENHANCING INNOVATION AND COMPETITIVENESS WORLDWIDE, 10., 2008, Madrid. Proceedings... Madrid: Global. Business and Technology Association (GBATA), 2008. p. 1012-1019.

SCHULTE-NÖLKE, H. The Brave New World of EU Consumer Law-Without Consumers, or Even Without Law? Journal of European Consumer and Market Law, v. 4, p. 135-139, 2015.

SCHWARTZ, D. S. Enforcing Small Print to Protect Big Business: Employee and Consumer Rights Claims in an Age of Compelled Arbitration. Wisconsin Law Review, United States, v. 1, p. 33, 1997.

SHETH, J. N.; MITTAL, B.; NEWMAN, B. I. Comportamento do cliente: indo além do comportamento do consumidor. São Paulo: Atlas, 2001.

SIGELMAN, L.; SMITH, R. E. consumer legislation in the american states: an attempt at explanation. Social Science Quarterly, United Kindgom, v. 61, n. 1, p. 58-70, June 1980.

SILVA, M. A.; URDAN, A. T. O Conhecimento do Consumidor sobre Preços: Um Exame de Produtos de Oito Categorias de Bens Duráveis. RAM - Revista de Administração Mackenzie, São Paulo, v. 9, n. 2, p. 82-103, 2008.
SIQUEIRA, M. L. Extensão da Responsabilidade Civil do Agente de Turismo frente ao Consumidor na Legislação Brasileira. Turismo em Análise, São Paulo, v. 6, n. 2, p. 82-95, nov. 1995.

SMITH, A. K.; BOLTON, R. N. The Effect of consumers emotional responses to service failures on their recovery effort evaluation and satisfaction judgments. Journal of the Academy of Marketing Science, United States, v. 30, n. 1, p. 5-23, 2002.

TAKIO, C. O. A Prestação de Serviços Turísticos e o Código de Defesa do Consumidor: Um Estudo das Reclamações de Turistas ao Procon. Turismo em Análise, São Paulo, v. 7, n. 1, p. 93-106, maio 1996.

TEFFÉ, C. A. S. A importância do código de defesa do consumidor para a sociedade brasileira: considerações sobre a sua elaboração, aplicação e atualização. In: JORNADA BRASILCON DE ATUALIZAÇÃO DO CÓDIGO DE DEFESA DO CONSUMIDOR, 13., 2013, Rio de Janeiro. Anais... Rio de Janeiro: Brasilcon, 2013. p. 1-26.

TEIXEIRA, E. B. A análise dos dados na pesquisa científica. Importância e desafios em estudos organizacionais. Desenvolvimento em Questão, Ijuí, v. 1, n. 2, p. 177-201, 2003.

VELLOSO, V. F.; YANAZE, M. H. O consumidor insatisfeito em tempo de redes sociais. Revista ECCOM, São Paulo, v. 5, n. 9, p. 7-20, jan./jun. 2014.

WADA, R. M.; OLIVEIRA, F. L. 22 anos de código de defesa do consumidor. GV Executivo, Rio de Janeiro, v. 12, n. 1, p. 18-21, jan./jun. 2013.

WARD, J.; OSTROM, A. Complaining to the masses: the role of protest framing in customercreated complaint web sites. Journal of Consumer Research, United States, v. 33, n. 2, p. 220-230, jul. 2006. 